\title{
SOSTENIBILIDAD AMBIENTAL
}

\section{JORNADA CEIA3: HUELLA AMBIENTAL}

¿Cómo ser más competitivo ecoinnovando? La huella ambiental de productos agroalimentarios. Estrategias y resultados.

Córdoba, Jueves 15 de Noviembre de 2012
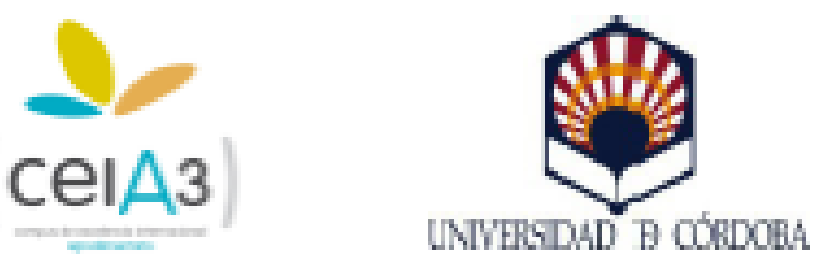


\section{SOSTENIBILIDAD AMBIENTAL Herba Ricemills SLU - Presentación}

\section{Herba Ricemills SLU, en pocas palabras}

- Filial Española del grupo Ebro Foods SA

- EF es el líder mundial de la comercialización de arroz y el numero dos en pasta.

- EF tiene filiales repartidas en mas de 23 países repartidas en Europa, América, Asia, África del Norte y tiene un portfolio de mas de 60 marcas.

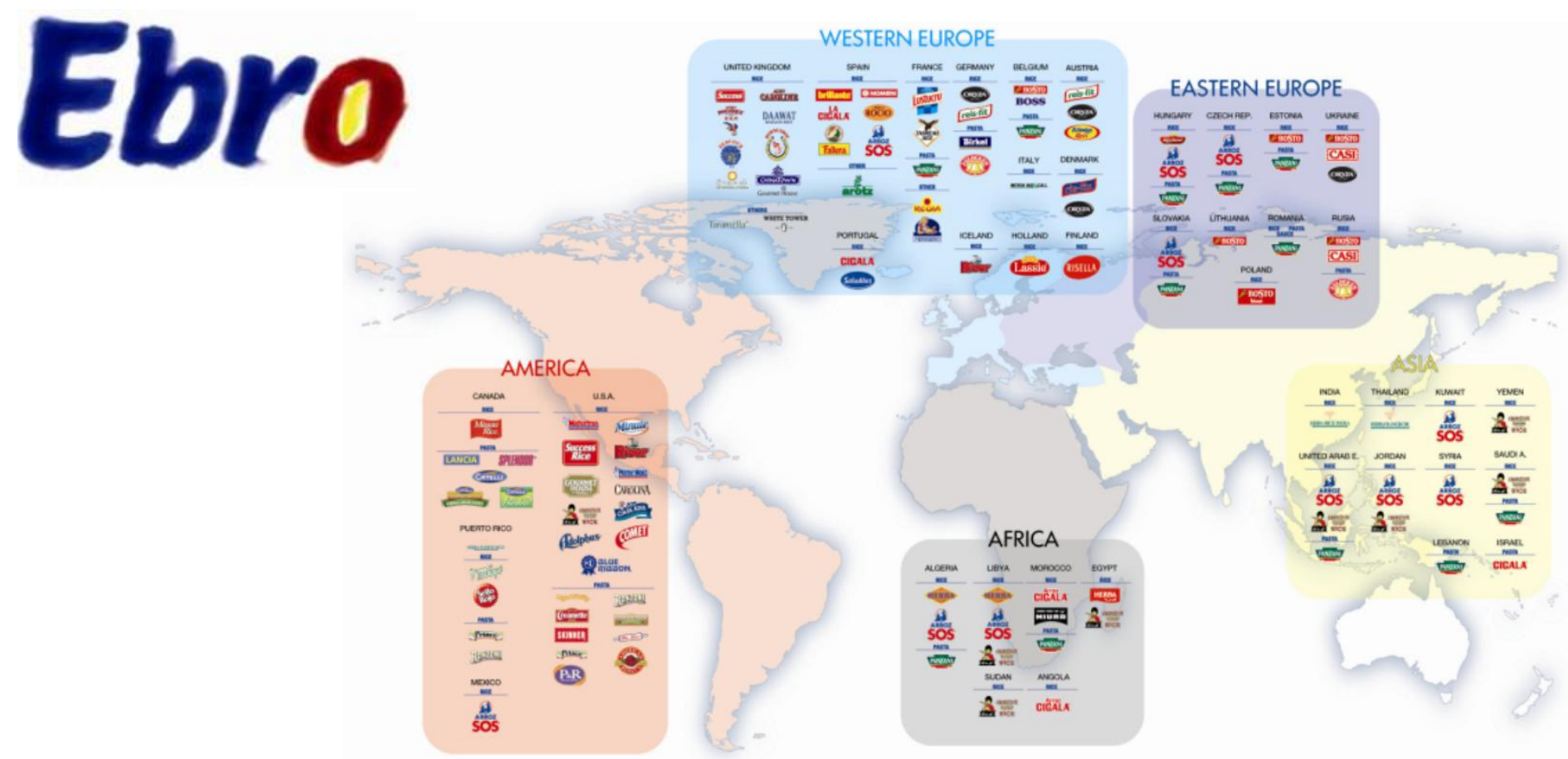




\section{SOSTENIBILIDAD AMBIENTAL}

Herba Ricemills SLU - Presentación

\section{Herba Ricemills SLU, en pocas palabras}

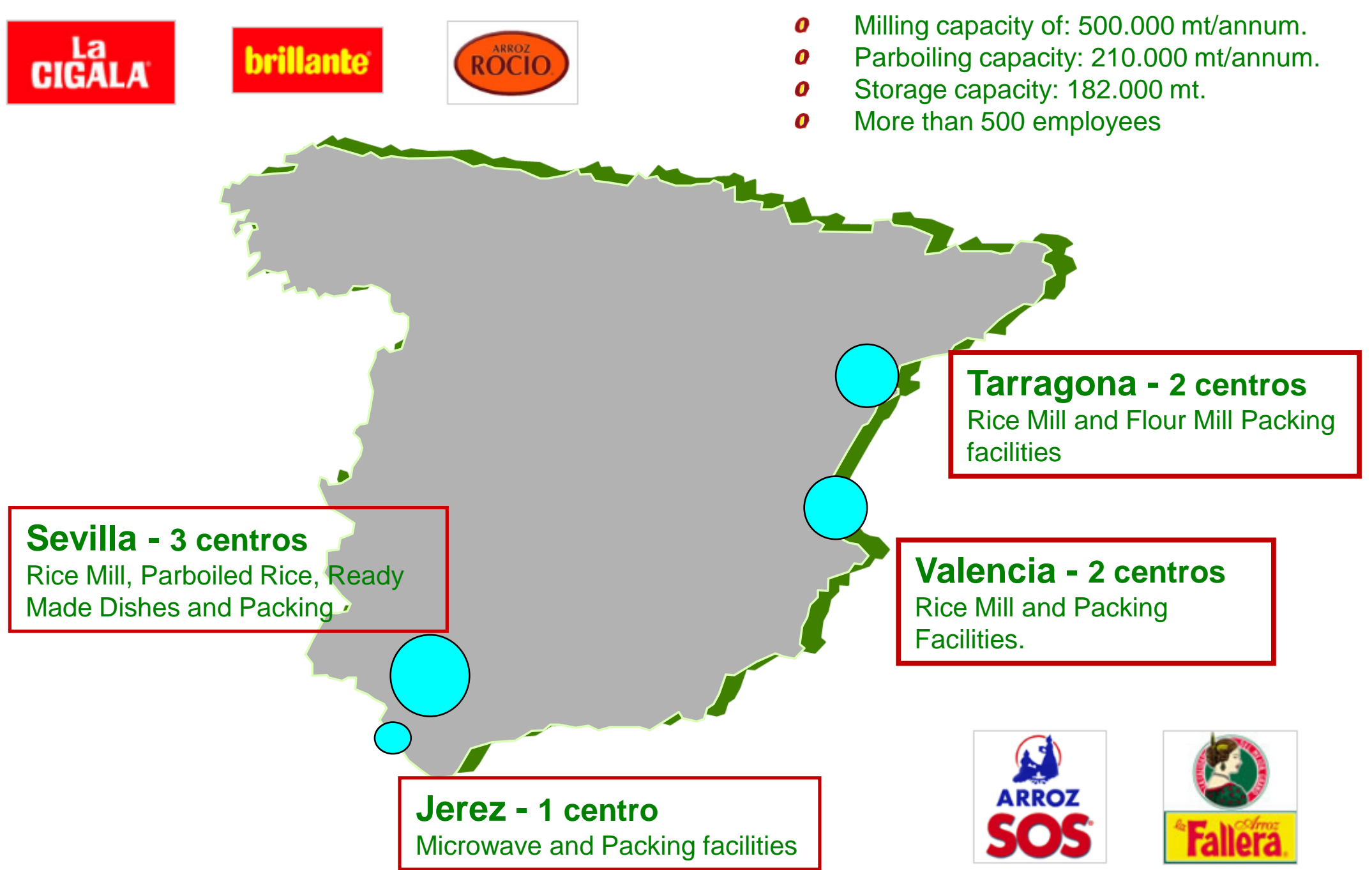




\section{SOSTENIBILIDAD AMBIENTAL}

Herba Ricemills SLU

Herba Ricemills y la sostenibilidad ambiental.

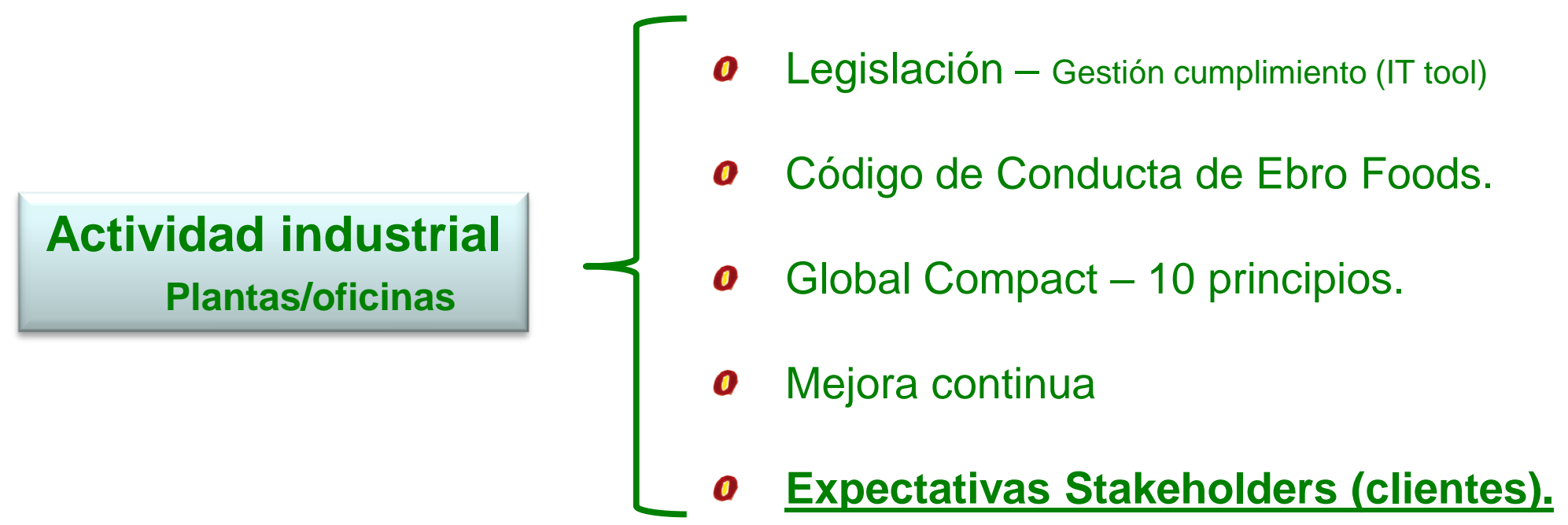

Materia prima agrícola sostenible 


\section{SOSTENIBILIDAD AMBIENTAL}

\section{Herba Ricemills SLU}

Herba Ricemills: cultivo sostenible del arroz.

Herba Ricemills ha iniciado un programa de trabajo en la zona de Sevilla dedicado a promover la sostenibilidad en el cultivo del arroz.

\section{Objetivos del provecto}

- Profundizar/adquirir el conocimiento científico necesario sobre los parámetros claves de sostenibilidad.

- Establecer estrategias posibles y reales que contribuyan a mitigar los impactos medioambientales - Buenas practicas agrícolas.

- Comunicar a los stakeholders relevantes los resultados obtenidos.

- Fomentar la aplicación de prácticas sostenibles de cultivo.

Este programa se esta desarrollando en colaboración con entidades locales (privadas y publicas) y la participación de diferentes clientes industriales. 


\section{SOSTENIBILIDAD AMBIENTAL}

Herba Ricemills SLU

Herba Ricemills: cultivo sostenible del arroz.

Iniciado a finales del año 2010, el programa aún está en fase inicial, habiéndose iniciados varios trabajos a medio-largo plazo en torno a los siguientes ejes:

- Optimización del abono nitrogenado y fosfórico

- Manejo del agua de riego y huella hídrica.

- Impacto de la salinidad sobre el cultivo.

- Optimización de las practicas agrícolas.

- Emisiones de GEls y huella de carbono.

En fase de estudio la puesta en marcha de otros proyectos asociados:

$\checkmark$ Impacto positivo del cultivo sobre la biodiversidad.

$\checkmark$ Impacto del arrozal sobre la calidad del agua - Filtro verde 


\section{SOSTENIBILIDAD AMBIENTAL}

Herba Ricemills SLU

Herba Ricemills: cultivo sostenible del arroz.

\section{Emisiones de GEls}

Una de las problemáticas en cuanto a la sostenibilidad ambiental del cultivo del arroz son las emisiones de GEls del suelo:

- Mas de $50 \%$ de las emisiones totales

- Difícil de medir /gran variabilidad

Herba Ricemills junto a dos grandes corporaciones, universidades y centros de investigación ha formado un consorcio para solicitar la puesta en marcha de un "Initial Training Network" (ITN) en el marco del "7th Framework Program" subvencionado por la UE.

Un ITN consiste en la contratación de estudiantes de tesis doctoral o postdoctoral para llevar a cabo trabajos de interés para el consorcio y éste, por su parte, provee a los estudiantes de una formación adicional destinada a mejorar su inserción laboral. 


\section{SOSTENIBILIDAD AMBIENTAL}

Herba Ricemills SLU

Herba Ricemills: cultivo sostenible del arroz.

El objetivo de este ITN será la realización de un proyecto sobre las emisiones de GEls en campos de arroz, pero con un enfoque global que se articulará en torno a los ejes siguientes:

- Mediciones directas de GEls en diferentes condiciones.

- Practicas de cultivo y mecanismos edáficos.

- Variedades y genética.

- Modelización (Predicción).

- Sostenibilidad en cadena de suministro - huella medioambiental.

- Sostenibilidad en agro-ecosistemas de arroz. 


\section{GRACIAS.}

